\title{
Full-Thickness Skin Grafts for Coverage of the Pedicle in Partial Second Toe Pulp Free Flap
}

\author{
Won Jin Cha (D), Jeong Hwa Seo (D), Jeeyoon Kim (D), Sung-No Jung (D), Bommie Florence Seo (D) \\ Department of Plastic and Reconstructive Surgery, College of Medicine, The Catholic University of Korea, Seoul, Korea
}

\begin{abstract}
Pedicle coverage during free flap reconstruction of the digit commonly presents complicated issues. As the finger is a cylindrical unit with small volume, it is difficult to secure ample soft tissue for relaxed coverage of the pedicle. We have applied full-thickness skin grafts (FTSGs) to loosely cover the pedicle of the free flap of the fingertip and report preliminary results. Seven patients who received free toe pulp flap and FTSG for soft tissue coverage of the pedicle were analyzed. Intraoperative parameters collected were defect, flap and graft area size and donor site. Patients were observed postoperatively for up to 2 months for graft take, necrosis, digit contour, and donor site complications. The average area of the free flap was $2.39 \pm 1.03 \mathrm{~cm}^{2}$ and the average graft area was $1.37 \pm 1.06 \mathrm{~cm}^{2}$. The FTSG survived without sloughing or necrosis in six patients. Early epithelial sloughing with dermis take was noted in one patient who healed with dressings. The pedicle and graft portion showed bulging immediately after the operation but decreased to normal contour by 4 weeks. FTSG is an option that can be safely used as a method of pedicle coverage during free flap reconstruction of digits.
\end{abstract}

Keywords: Fingertip injuries; Free tissue flaps; Graft survival

\section{Introduction}

Small free flaps have become an invaluable option for reconstruction of the fingertip. The partial second toe pulp free flap is optimal, providing well vascularized glabrous tissue from the tibial aspect of the second toe. The dimensions of the pedicle are well matched to the digital vessels, and donor site morbidity is negligible [1]. Other options for small volume reconstruction include the great toe pulp free flap, the toe plantar flaps, hypothenar free flap, radial artery superficial palmar branch flap, ulnar artery perforator flap, radial artery perforator flap, dorsoradial artery perforator flap, and dorsoulnar artery perforator flap [2-4].

Insetting the small free flap is relatively straightforward, as most fingertip defects will require anastomosis to one of the digital arteries. Most of the time however, the small cylindrical geometry of the finger is too snug to allow relaxed coverage of the pedicle. Tension on the pedicle may lead to vascular compromise and consequently flap failure. Studies have investigated methods of pedicle coverage, including adipofascial flaps and skin grafts [5,6]. Leaving the pedicle exposed, or coverage with artificial materials may risk desiccation or necrosis $[7,8]$.

Han and Min [9] have studied the safety of applying a split-thickness skin graft (STSG) over the pedicle of a variety of free flaps. They have postulated that the vascular supply from the pedicle directly beneath the graft increases the proportion of graft take. However, the split-thickness graft requires a dermatome for harvest, which is disadvantageous for the tiny areas of skin required on the digit pedicle. An alternative

\section{Ideas and Innovations}

Received: October 9, 2021

Revised: October 15, 2021

Accepted: October 15, 2021

\section{Corresponding author:}

Bommie Florence Seo, M.D., Ph.D.

Department of Plastic and Reconstructive Surgery, Uijeongbu St. Mary's Hospital, College of Medicine, The Catholic University of Korea, 271 Cheonbo-ro, Uijeongbu 11765, Korea Tel: +82-31-820-3074

Fax: +82-31-874-0301

E-mail: bommiefseo@catholic.ac.kr

This is an Open Access article distributed under the terms of the Creative Commons Attribution Non-Commercial License (https://creativecommons.org/licenses/by-nc/4.0/) which permits unrestricted non-commercial use, distribution, and reproduction in any medium, provided the original work is properly cited.

C) 2021 Korean Wound Management Society 
is placing a full-thickness skin graft (FTSG) over the pedicle by obtaining a small area of full-thickness skin, which can come from almost any region of the body such as the volar wrist, hypothenar or thenar eminence, or from the foot.

\section{Ideas}

\section{Patients and surgical techniques}

A small FTSG was performed for patients who underwent free partial second toe pulp transfer reconstruction for fingertip defects between January 2019 to January 2020 who required additional pedicle coverage. Patient photographic consent was obtained in written form for all patients. This study was approved by the Institutional Review Board of Uijeongbu St. Mary's Hospital (IRB No. UC21ZISI0132).

The shape and dimensions of the defect were measured under local or general anesthesia after the recipient finger was debrided until a healthy bed was exposed. After the free flap was harvested and inset according to previously discussed methods, any soft tissue defect overlying the anastomosed digital artery and donor artery was covered with a FTSG [1]. While an FTSG can be harvested virtually anywhere in the body given that it has enough redundant skin for tension-free closure, we preferred to harvest skin from the infra-malleolar region ipsilateral to the flap donor site, save for a single case. This area was chosen because it was in the same surgical field as the partial second toe pulp free flap, was a non-hair bearing location, and could avoid conspicuous scars. The donor site for case no. 2 was the hypothenar eminence of the ipsilateral hand because the patient requested ambulation early after the operation. The harvested skin was sutured to the margins of the defect using \#5-0 nylon sutures, and then additional fixa- tion was applied by spraying a fibrin sealant (Tisseel; Baxter Healthcare Corp., Deerfield, IL, USA) on the surrounding margins so that a thin layer of sealant connected and was overlying the graft and the adjacent skin [10]. This layer was not watertight, therefore allowed drainage of discharge or hemato$\mathrm{ma}$, and required ointment dressings to prevent desiccation.

\section{Postoperative care}

Dressings were changed daily using saline, ointment, and foam material with no additional compression applied to the graft. Both Mupirocin ointment (Esroban; JW Pharmaceutical Corp., Seoul, Korea) and recombinant human epithelial growth factor ointment (Easyef; Daewoong Pharmaceutical Corp., Seoul, Korea) were applied. The graft was lightly covered with a thin minimally adhesive foam dressing (Mepilex Lite; Mölnlycke Health Care, Gothenburg, Sweden).

\section{Results}

A total of seven patients were included in this study, two females and five males. Ages ranged from 42 to 63 years. Mean follow-up was $165 \pm 141$ days. The demographics are summarized in Table 1. Each patient received a partial second toe pulp free flap for one digit. One male patient was a current smoker, one male patient was an ex-smoker, and the others were nonsmokers. Three patients were taking medication for hypertension, one person for diabetes mellitus. Five had experienced work-place related crushing injuries from industrial machinery, one sustained an amputation from farm work, and one person was injured by a heavy door. The average defect area was $3.78 \pm 1.98 \mathrm{~cm}^{2}$. The average area of the free flap was $2.39 \pm$ $1.03 \mathrm{~cm}^{2}$ and average graft area for the pedicle was $1.37 \pm 1.06$ $\mathrm{cm}^{2}$. The flap survived without loss in all patients. Six of the

Table 1. Patient demographics

\begin{tabular}{|c|c|c|c|c|c|c|c|}
\hline Case No. & Sex & Age (yr) & Injury type & Injury mechanism & Medical history & Smoking history & $\begin{array}{c}\text { Follow-up } \\
\text { duration (day) }\end{array}$ \\
\hline 1 & Male & 42 & Crushing & Industrial machinery & HTN & Ex-smoker & 39 \\
\hline 2 & Male & 58 & Crushing & Farm work & None & None & 206 \\
\hline 3 & Male & 51 & Amputation & Industrial machinery & None & None & 43 \\
\hline 4 & Female & 63 & Amputation & Industrial machinery & HTN, DM, dyslipidemia & None & 439 \\
\hline 5 & Male & 54 & Amputation & Heavy door & None & Current & 229 \\
\hline 6 & Male & 43 & Crushing & Industrial machinery & None & None & 97 \\
\hline 7 & Female & 58 & Amputation & Industrial machinery & HTN & None & 105 \\
\hline Mean $\pm S D$ & & 52.7 & & & & & $165 \pm 141$ \\
\hline
\end{tabular}

HTN, hypertension; DM, diabetes mellitus. 
grafts survived and were well-taken by the second week after surgery, but epithelial sloughing was seen after repeated hematoma collection was found in one patient (case no. 1) (Fig. 1). The graft healed during the following 2 weeks using recombinant human epithelial growth factor ointment dressings. Initially, the graft bulged out from the digit's smooth contour, but as the flap became stable and swelling decreased, this volume irregularity normalized (case no. 1) (Fig. 2). By 8 weeks the texture and contour were almost identical to that of the surround-

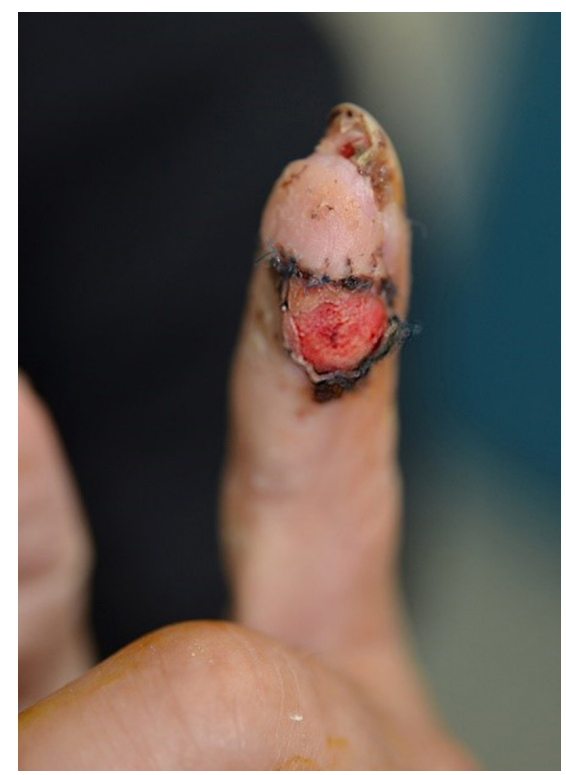

Fig. 1. Epithelial sloughing of a full-thickness skin graft (FTSG). Sloughing of the FTSG was seen at 20 days after the graft in the left index finger (case no. 1). ing digit skin (case no. 2) (Fig. 3). All donor sites healed by the second week after surgery when sutures were removed without disruption. Operative details are summarized in Table 2.

\section{Discussion}

The geometry of the digit forms the slimmest cylinder of the human body. Coverage of the anastomosis or pedicle is often required to prevent strangulation by local tissue. Skin grafts have often been used to provide shelter for the pedicle in free or pedicled flaps. Some authors have weighed against this option, deeming it endangering the vessels. STSGs have a thickness of $0.25 \mathrm{~mm}$ to $0.5 \mathrm{~mm}$, barely providing any tissue volume, and therefore may seem quite fragile. However, Han and Min [9] have applied STSGs to overlie various flap pedicles of the body, and have found that they were more durable than previously asserted [9]. Their hypothesis is that the adventitia of the vessels were the optimal bed for graft take, supplying direct vascular ingrowth.

While the authors have experience applying STSGs to pedicles, muscles, or other areas of hand skin defects, we have found that harvesting the STSG and manipulating the thin graft during surgery is cumbersome. Harvesting a tiny STSG will require use of a small blade (such as the Humby dermatome or razor blade) which is hardly used in the modern operating room. Using a pneumatic dermatome, even the smallest blade will result in surplus harvest, unnecessarily increasing the donor area. Being depleted of most of the dermis, fixation requires gentle technique to prevent the graft from damage.
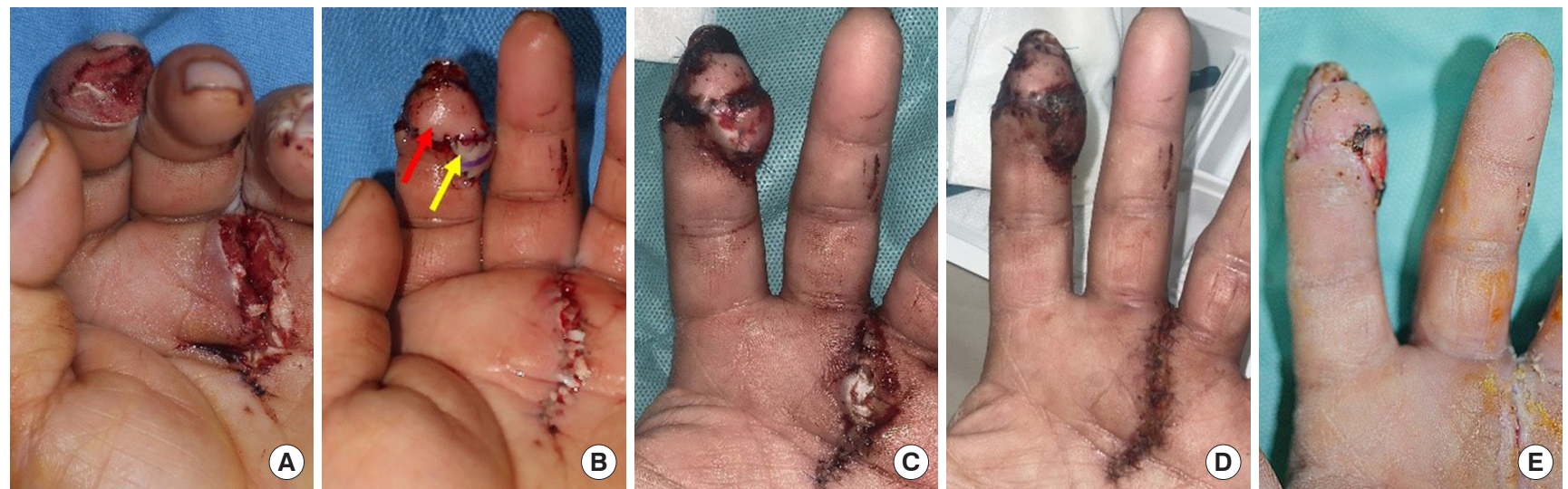

Fig. 2. Contour changes of a full-thickness skin graft (FTSG). Changes in the contour of the FTSG over the span of 3 weeks in case no. 1. (A) Preoperative photograph of the volar pulp defect of the index finger, laceration of the palm and ring finger. (B) Immediately after free flap inset and FTSG (red arrow: flap, yellow arrow: FTSG). (C) Three days after grafting, the graft and underlying tissue seem to protrude from the finger. (D) Ten days postoperatively, decrease in edema. (E) Twenty days after the operation, digit contour is almost normal, but sloughing of the graft is seen. 

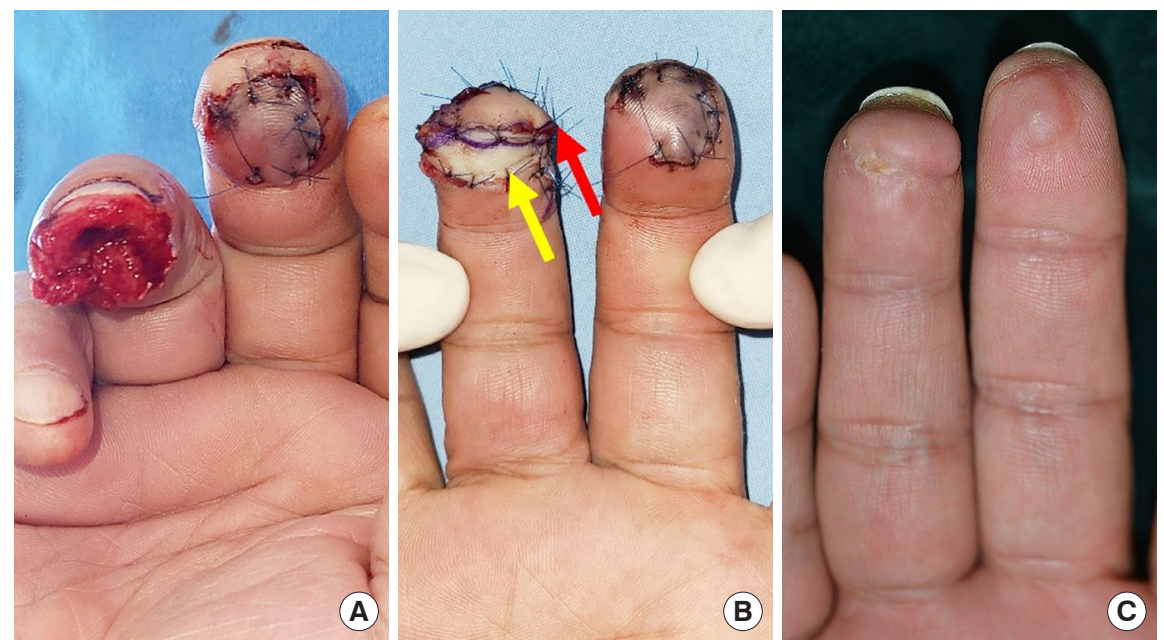

Fig. 3. Right ring fingertip defect caused by a lawnmower (case no. 2). (A) Preoperative photograph shows the volar pulp defect of the ring finger and an avulsive laceration of the middle finger. (B) Immediate after free flap inset and full-thickness skin graft (FTSG) of the ring finger, and closure of the middle finger (red arrow: flap, yellow arrow: FTSG). (C) The skin texture and contour at 8 weeks after surgery.

Table 2. Operative data

\begin{tabular}{|c|c|c|c|c|c|c|c|}
\hline Case №. & Inflicted digit & Flap donor & Graft donor & Defect size $\left(\mathrm{cm}^{2}\right)$ & Flap size $\left(\mathrm{cm}^{2}\right)$ & FTSG size $\left(\mathrm{cm}^{2}\right)$ & Complication \\
\hline 1 & Lt. index fingertip & Lt. second toe & Lt. ankle & $2.5 \times 1$ & $1.9 \times 0.8$ & 0.76 & FTSG sloughing \\
\hline 2 & Rt. ring fingertip & Lt. second toe & Lt. ankle & $2 \times 2$ & $2.2 \times 0.9$ & 1.96 & None \\
\hline 3 & Rt. middle fingertip & Rt. second toe & Rt. hypothenar eminence & $3 \times 1.3$ & $2.1 \times 1.3$ & 1.36 & None \\
\hline 4 & Rt. ring fingertip & Lt. second toe & Lt. ankle & $1.8 \times 1.5$ & $1.7 \times 1.2$ & 0.68 & None \\
\hline 5 & Lt. ring fingertip & Rt. great toe & Rt. ankle & $4 \times 2$ & $2.5 \times 1.5$ & 3.50 & None \\
\hline 6 & Lt. middle fingertip & Lt. second toe & Lt. ankle & $1.5 \times 1.5$ & $1.7 \times 0.9$ & 0.72 & None \\
\hline 7 & Rt. Index fingertip & Lt. second toe & Lt. ankle & $2.5 \times 1.2$ & $2.2 \times 1.1$ & 0.58 & None \\
\hline Mean \pm SD & & & & $3.78 \pm 1.98$ & $2.39 \pm 1.03$ & $1.37 \pm 1.06$ & \\
\hline
\end{tabular}

FTSG, full-thickness skin graft; Lt, left; Rt, right.

Because the flap is usually well vascularized, oozing from the vicinity threatens loss of the thin graft during postoperative care. The FTSG, on the other hand, is easily harvested in any small dimension required, and does not necessitate use of the dermatome. Donor site closure results in elimination of any raw surface as in STSGs. The largest advantage is that FTSGs include a sturdy layer of dermis that provides structure for suture fixation and contributes to a thicker layer of coverage for the pedicle. Although this additional tissue may increase oxygen or nutrient demand, and together with the lack of compressive dressings be a cause for failure to take, we think that the abundance in vascularity just beneath the graft was the key factor that enabled stable tissue engraftment.

In the partial second toe pulp free flap, the digital nerves are anastomosed near the digital arteries, and therefore the fact that the graft will also be directly overlying the nerve should be taken into consideration. The fingertip is exposed to constant friction and pressure, and long-term durability comparison studies should be performed in the future.

This study is limited by its small sample size and lack of control group. Future large-scale studies comparing the FTSG with STSG to cover pedicles are warranted to discern which method is more optimal. However, our preliminary results suggest that the FTSG is a feasible option for coverage of the pedicle in free flap fingertip reconstruction.

\section{Conflict of interest}

No potential conflict of interest relevant to this article was reported. 


\section{ORCID iDs}

Won Jin Cha

https://orcid.org/0000-0003-0761-4251

Jeong Hwa Seo

https://orcid.org/0000-0002-0911-4747

Jeeyoon Kim

https://orcid.org/0000-0002-2445-3720

Sung-No Jung https://orcid.org/0000-0002-0419-4717

Bommie Florence Seo

https://orcid.org/0000-0002-6907-5962

\section{References}

1. Lee DC, Kim JS, Ki SH, et al. Partial second toe pulp free flap for fingertip reconstruction. Plast Reconstr Surg 2008; 121:899-907.

2. Ono S, Sebastin SJ, Ohi H, et al. Microsurgical flaps in repair and reconstruction of the hand. Hand Clin 2017;33: 425-41.

3. Seo BF, Kwon BY, Han HH. Sensate hypothenar perforator free flap for resurfacing large volar surface defect of the digit. Microsurgery 2018;38:419-22.

4. Yang JW. Anatomical variations of the innervated radial artery superficial palmar branch flap: a series of 28 clinical cases. Arch Plast Surg 2020;47:435-43.

5. Durand PD, Couto RA, Isakov R, et al. Adipofascial flap in the recipient incision site for coverage of vascular pedicle in free tissue transfer. Plast Reconstr Surg 2016;137:103941.

6. Maan ZN, Legrand A, Long C, et al. Reverse radial forearm flap. Plast Reconstr Surg Glob Open 2017;5:e1287.

7. Hallock GG. Methods for providing vascularized tissue protection of microanastomoses. Ann Plast Surg 1991;27: 305-11.

8. Turfe Z, Timek EK, Timek EK. The application of a bilaminate skin substitute as a temporary coverage of a free flap pedicle. Microsurgery 2015;35:79-80.

9. Han HH, Min KH. Is split-thickness skin graft safe for coverage of the vascular pedicle in free tissue transfer? J Plast Surg Hand Surg 2019;53:138-42.

10. Han HH, Jun D, Moon SH, et al. Fixation of split-thickness skin graft using fast-clotting fibrin glue containing undiluted high-concentration thrombin or sutures: a comparison study. Springerplus 2016;5:1902. 